\title{
In vivo and in vitro studies on Anaplasma phagocytophilum infection of the myeloid cells of a patient with chronic myelogenous leukaemia and human granulocytic ehrlichiosis
}

\author{
M Bayard-Mc Neeley, A Bansal, I Chowdhury, G Girao, C B Small, K Seiter, J Nelson, D Liveris, \\ I Schwartz, D F Mc Neeley, G P Wormser, M E Aguero-Rosenfeld
}

J Clin Pathol 2004;57:499-503. doi: 10.1136/icp.2003.011775

See end of article for authors' affiliations

.....................

Correspondence to: DrM E Aguero-Rosenfeld, Clinical Laboratories Room 1J-04, Westchester Medical Center, Valhalla, NY 10595, USA: m_aguero-rosenfeld@ nymc.edu

Accepted for publication 26 October 2003

\begin{abstract}
Aims: The occurrence of human granulocytic ehrlichiosis (HGE) in a patient with chronic myelogenous leukaemia (CML) provided an opportunity to study whether Anaplasma phagocytophilum, the aetiological agent of HGE, infects mature or immature cells, both in vivo and in vitro.

Methods: Diagnosis of HGE was confirmed by culture, polymerase chain reaction (PCR), detection of intragranulocytic inclusions, and serology. The infection rates of different myelogenous stages of granulocytic differentiation were determined by microscopy. Anaplasma phagocytophilum infection of the bone marrow was analysed by PCR, culture, and microscopy. In addition, the in vitro growth of A phagocytophilum in the patient's granulocytes and in $\mathrm{HL}-60$ cells (a promyelocytic leukaemia cell line) was compared.

Results: Pretreatment blood smears showed that mature granulocytic cells had a higher infection rate with A phagocytophilum than did immature cells. In the original inoculation of the patient's cells into HL-60 cells to isolate $A$ phagocytophilum, the bacterium grew faster in the patient's leukaemic cells than in $\mathrm{HL}-60$ cells. Anaplasma phagocytophilum inclusions were rarely seen in bone marrow granulocytes and PCR was negative. In vitro, two A phagocytophilum isolates grew faster in the patient's granulocytes than in $\mathrm{HL}-60$ cells.

Conclusions: The superior growth in CML cells compared with $\mathrm{HL}-60$ cells suggests that $A$ phagocytophilum preferentially infects mature granulocytes. The higher infection rate of the patient's mature versus immature granulocytes before treatment and the minimal level of infection of the patient's bone marrow support this. It is possible that the primary site of infection in HGE is the peripheral mature granulocytic population.
\end{abstract}

"Infection may be particularly severe in the elderly or in those who are immunocompromised, with a reported mortality rate in the USA of up to $5 \%$ "

Patients with HGE characteristically present with fever, leucopenia, thrombocytopenia, and increases in liver enzymes. ${ }^{8}{ }^{9}$ Infection may be particularly severe in the elderly or in those who are immunocompromised, with a reported mortality rate in the USA of up to $5 \% .{ }^{8}{ }^{10}$

We recently encountered a patient who presented with fever and abnormalities of multiple systems, and was diagnosed to have both chronic myelogenous leukaemia (CML) and HGE. Because of the tropism of A phagocytophilum for granulocytic cells, we investigated the ability of this bacterium to infect different stages of the myeloid series in vivo by analysing the infection rate of different cell populations in stained blood smears before antimicrobial treatment. After the patient completed treatment with doxycycline, we studied the ability of the patient's cells to become infected with two A phagocytophilum isolates.

\section{CASE REPORT}

A 78 year old male resident of rural upstate New York presented in June 2000 with a three day history of fever, chills, and shortness of breath. On admission, his temperature was $38.4^{\circ} \mathrm{C}$, pulse 103 beats/minute, respiratory rate 24 breaths/minute, and blood pressure 124/56 mm Hg. Fine crackles were auscultated bilaterally at the lung bases. The heart rate was regular and there were no murmurs or bruits. The liver was palpable, $5 \mathrm{~cm}$ below the right costal margin, and the spleen was palpable $20 \mathrm{~cm}$ below the left costal margin. Table 1 shows the complete blood cell count (CBC) and selected chemistry parameters.

Initial treatment included hydroxyurea and allopurinol for CML, and heparin, nitropaste, metoprolol, and acetylsalicylic

Abbreviations: CML, chronic myelogenous leukaemia; HGE, human granulocytic ehrlichiosis; PCR, polymerase chain reaction; PSGL-1, P selectin glycoprotein ligand-1; WBC, white blood cell count 
Table 1 Results of selected laboratory tests by hospital day

\begin{tabular}{llllllll}
\hline & \multicolumn{7}{l}{ Hospital day } \\
\cline { 2 - 8 } Test (normal range) & $\mathbf{1}$ & $\mathbf{2}$ & $\mathbf{3}$ & $\mathbf{5}$ & $\mathbf{1 0}$ & $\mathbf{1 4}$ & $\mathbf{3 1}$ \\
\hline WBC $\times 10^{9} / /(4.7-10.7)$ & 157.5 & 136.2 & 107 & 53.8 & 78 & 87.2 & 13.3 \\
Platelets $\times 10^{9} / /(160-410)$ & 505 & 365 & 307 & 130 & 202 & 453 & 216 \\
BUN mg/l (60-220) & 340 & 430 & 840 & 1170 & 580 & 400 & 350 \\
Creatinine mg/l (4-12) & 17 & 20 & 31 & 53 & 57 & 42 & 17 \\
AST IU/ml (4-35) & 71 & 171 & 164 & 120 & 35 & 25 & 28 \\
ALT IU/ml (2-40) & 35 & 53 & 48 & 40 & 29 & 22 & 25 \\
Troponin I ng/ml (0.3-2.0) & 5.4 & 91.7 & 184 & 48.7 & 6 & 1 & NA \\
CKMB ng/ml (0.7-10.0) & 12.3 & 79.6 & 45.8 & 11.8 & 3.5 & 3.5 & NA \\
\hline
\end{tabular}

Treatment with doxycycline was initiated on hospital day 3.

ALT, alanine aminotransferase; $A S T$, aspartate aminotransferase; $B U N$, blood urea nitrogen; CKMB, creatine kinase MB fraction; NA, not available; WBC, white blood cell count.

acid for a presumed non-Q wave myocardial infarction. Empirical antibiotic treatment was initiated with cefepime and vancomycin. On the second day of hospitalisation the patient developed respiratory distress, with wheezing and coarse rales bilaterally. A chest radiograph at this time revealed bilateral diffuse interstitial infiltrates. His temperature increased to $40^{\circ} \mathrm{C}$. He became progressively hypoxic and hypotensive and was intubated.

On the third hospital day, approximately $2 \%$ of the neutrophils in the peripheral blood smear were first noted to contain cytoplasmic inclusions (morulae), suggestive of HGE. A bone marrow aspirate showed pronounced hypercellularity and myeloid hyperplasia. Cytogenetic studies of a bone marrow sample revealed a karyotype of $46, \mathrm{XY}, \mathrm{t}(9 ; 22)$, $(\mathrm{q} 34 ; \mathrm{q} 11.2)$ in $93 \%$ of the cells, confirming a diagnosis of chronic phase CML. In addition, the bone marrow aspirate smear showed occasional intragranulocytic inclusions, suggestive of $A$ phagocytophilum infection. Serum tested positive for antibodies to Borrelia burgdorferi by an IgG/IgM enzyme linked immunosorbent assay and IgG immunoblot according to Centres for Disease Control criteria. ${ }^{11}$

Doxycycline was added at a dose of $100 \mathrm{mg}$ intravenously every 12 hours. Over the next three days, the patient required packed red blood cell transfusions and the administration of intravenous vasopressor and inotropic agents for cardiovascular support. He developed non-oliguric acute renal failure requiring temporary haemodialysis. However, on the fifth day of hospitalisation he became afebrile and began to improve clinically; he was extubated on the 10th day of hospitalisation and was removed from intensive care four days later. He completed 21 days of doxycyline treatment for HGE and was discharged after one month of hospitalisation.

\section{MATERIALS AND METHODS}

\section{Evaluation of HGE infection}

Peripheral blood smears were stained with Wright's stain, and 1000 granulocytes were classified according to the stage of development and examined for inclusions of A phagocytophilum. ${ }^{9}$ Buffy coat smears were also prepared, stained with Wright's, and examined for A phagocytophilum inclusions.

Blood and bone marrow aspirates collected in EDTA were inoculated into HL-60 cells, a human promyelocytic leukaemia cell line, for culture of $A$ phagocytophilum, as described previously. ${ }^{4}$ Briefly, $0.2 \mathrm{ml}$ of blood or bone marrow was inoculated into a flask containing $5 \mathrm{ml}$ of HL-60 cells at a cell density of $2 \times 10^{5} / \mathrm{ml}$ in RPMI 1640 medium with Lglutamine (Sigma Inc, St Louis, Missouri, USA) containing $10 \%$ of fetal bovine serum and incubated at $37^{\circ} \mathrm{C}$ with $5 \%$ $\mathrm{CO}_{2}$. Culture aliquots were removed daily, cytocentrifuged, and stained with Wright's to determine the rate of infection. HL-60 cells are promyelocytic leukaemic cells with distinctive morphological features and were clearly distinguished from the patient's mostly mature leukaemic cells.

Blood and bone marrow specimens were tested by a nested polymerase chain reaction (PCR) with primers to amplify the groESL region of $A$ phagocytophilum. ${ }^{12}$

Acute and convalescent phase specimens were tested for antibodies in an in house indirect immunofluorescent antibody assay using a local $A$ phagocytophilum isolate (NY-13) as the source of antigen, as described previously. ${ }^{13}$

\section{In vitro infection of patient and normal donor cells with different $\boldsymbol{A}$ phagocytophilum isolates}

After obtaining informed consent, blood samples were collected in EDTA from the patient, approximately one month after completion of antimicrobial treatment, and from a healthy control. The patient's peripheral blood count at this time revealed a white blood cell count (WBC) of $46.2 \times 10^{9}$ cells/litre, with the differential count showing $3 \%$ promyelocytes, $7 \%$ metamyelocytes, $10 \%$ myelocytes, $2 \%$ bands, $62 \%$ polymorphonuclear neutrophils, $7 \%$ lymphocytes, $9 \%$ monocytes, and a platelet count of $346 \times 10^{9}$ /litre. Blood from a healthy donor had a WBC of $8.2 \times 10^{9}$ cells/litre, with a differential showing $66 \%$ granulocytes, $7 \%$ monocytes, and $27 \%$ lymphocytes. Buffy coats were prepared from both specimens, red blood cells were lysed in hypotonic saline, and white blood cells were resuspended at a concentration of $5 \times 10^{5} / \mathrm{ml}$ in RPMI 1640 containing $10 \%$ fetal bovine serum. Two separate flasks each containing $5 \mathrm{ml}$ of the patient's or the healthy donor's cell suspensions, as described above, were inoculated with suspensions of HL-60 cells infected with either the patient's own A phagocytophilum isolate (NY33 ) or another human isolate (NY-37) cultured in our laboratory during the summer of 2000. Separate flasks with healthy donor or patient cells were incubated without the addition of $A$ phagocytophilum as control. For comparison, both $A$ phagocytophilum isolates were also inoculated into HL60 cell lines as described in the culture methods. All flasks were incubated at $37^{\circ} \mathrm{C}$ under $5 \% \mathrm{CO}_{2}$ and cultures were monitored daily for the presence of HGE inclusions. ${ }^{4}$

\section{RESULTS}

Evaluation of infection with $A$ phagocytophilum in the patient's peripheral blood granulocytes during acute phase HGE

Infection was observed in different stages of granulocytes by direct examination of peripheral blood smears during the first three days of hospitalisation before doxycycline treatment (table 2). Polymorphonuclear neutrophils were the only cells found to be infected on the first day of hospitalisation, with the absolute number of infected granulocytes in peripheral blood being $0.158 \times 10^{9}$ /litre. The number of infected granulocytes steadily increased to $2.0 \%\left(2.3 \times 10^{9}\right.$ /litre $)$ on 
Table 2 Anaplasma phagocytophilum infection of different granulocyte stages on peripheral blood smear during the first three days of hospitalisation, before treatment with doxycycline

\begin{tabular}{llll}
\hline & \multicolumn{3}{l}{ Day of hospitalisation } \\
\cline { 2 - 4 } & Day 1 & Day 2 & Day 3 \\
\hline Total WBC infected $\times 10^{9} / \mathrm{I}$ & 157.5 & 143.5 & 116.5 \\
Differential WBC (\%)* & $40(0.25)$ & $38(0.52)$ & $61.3(1.9)$ \\
Granulocytes & 10 & 13 & $5.1(7.5)$ \\
Bands & 20 & $25(1)$ & $11.7(0.8)$ \\
Metamyelocytes & 10 & $13(0.4)$ & $3.1(3)$ \\
Myelocytes & 10 & 3 & $11.1(1.7)$ \\
Promyelocytes & 2 & 6 & 2.9 \\
Basophils & 2 & 1 & 0.8 \\
Eosinophils & 3 & 0 & 1 \\
Monocytes & 2 & 1 & $2(4.8)$ \\
Myeloblasts & 1 & 0 & 1 \\
Lymphocytes & 0.1 & 0.5 & 2.0 \\
Per cent of total WBC infected & \multicolumn{4}{l}{} \\
\hline *Numbers in parenthesis refer to per cent of infection at the different cell \\
stages. \\
WBC, white blood cell count.
\end{tabular}

day 3, and included different myeloid stages (table 2; fig 1); the number of infected granulocytes declined rapidly after the initiation of antibiotic treatment.

In the initial blood culture to confirm the diagnosis of HGE, we found that the number of $A$ phagocytophilum inclusions increased in the patient's own cells before they were seen in the HL-60 cells (fig 2). The percentage of infected patient cells increased from $4 \%$ on day 1 to $22 \%$ on day 4 of culture, and individual patient cells contained more morulae/cell on day 4 than at the time the culture was first established. In contrast, the HL-60 cells showed very rare or no inclusions during the first three days of culture $\left(\mathrm{p}<0.001\right.$, Pearson $\left.\chi^{2}\right)$ and on day 4 reached an infection rate of $9 \%$. Table 3 shows a comparison of the absolute numbers of infected cells. Morphological changes of the patient's cells in culture made it difficult to determine their stage of differentiation and therefore to determine the infection rate of the different myeloid stages.

Culture of bone marrow first showed intracellular A phagocytophilum inclusions in HL-60 cells on day 3, with

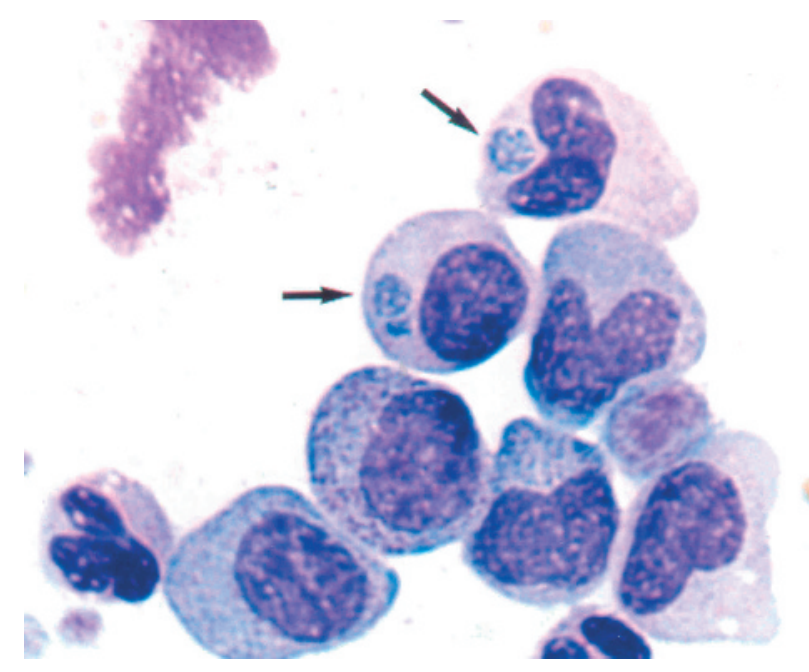

Figure 1 Photomicrograph of a buffy coat smear of the patient's blood collected on the third hospital day stained with Wright's stain. Anaplasma phagocytophilum inclusions are seen in the cytoplasm of two different granulocyte stages (a metamyelocyte and a myelocyte). Arrows indicate morulae.

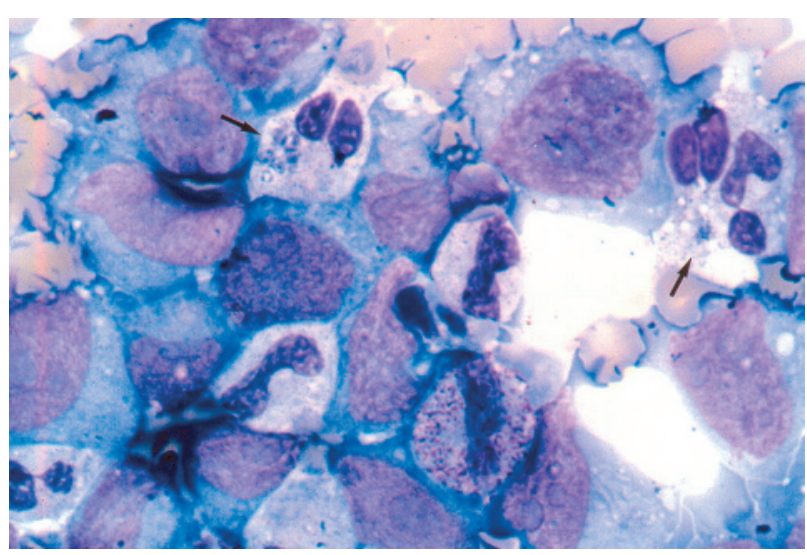

Figure 2 Photomicrograph of cytospin preparation from culture aliquots of the patient's blood obtained during the acute phase of human granulocytic ehrlichiosis after three days of culture incubation. Arrows show Anaplasma phagocytophilum inclusions in the patient's granulocytes. Several morulae are present in the cytoplasm of the granulocyte indicated with an arrow at the top left hand part of the figure. Infection is not seen in the surrounding HL-60 cells.

the infection rate of HL-60 cells peaking at $16 \%$ on day 9 . We also saw an increase in $A$ phagocytophilum inclusions in the cells of the patient's own bone marrow sample. These cells demonstrated rare A phagocytophilum inclusions at day 0; however, infection expanded at a slower rate than in HL-60 cells, showing a maximum of $8 \%$ infected cells on day 10 (data not shown).

PCR using groESL primers of the patient's peripheral blood before doxycycline treatment was positive for A phagocytophilum nucleic acid sequences; however, PCR on a bone marrow specimen was negative. PCR was negative on the blood specimen used in the in vitro studies collected one month after completion of doxycycline treatment.

The patient's sera tested negative (titre $<80$ ) for antibodies to $A$ phagocytophilum by indirect immunofluorescent antibody assay on the fifth day of hospitalisation, but a convalescent titre of $\geqslant 2560$ was found on both the 13th and 22nd days of hospitalisation.

\section{In vitro infection of patient cells with two different isolates of $A$ phagocytophilum}

Under experimental conditions, the patient's granulocytes obtained after completion of doxycycline treatment supported growth of both A phagocytophilum isolates (NY-33 and NY-37) earlier than did HL-60 cells (table 4). Peripheral blood granulocytes from a healthy donor did not survive in culture to day 4 , and infection was not detected with either strain. No growth of A phagocytophilum was detected in the uninoculated control flasks. After day 6 of incubation, A phagocytophilum isolates steadily expanded in HL-60 cells, reaching higher rates of infection than in the patient's leucocytes after one week of incubation (data not shown).

\section{DISCUSSION}

We report a case of HGE in a patient with newly diagnosed CML in the chronic phase. The diagnosis of HGE was confirmed by the recovery of A phagocytophilum in culture from blood and bone marrow in the HL-60 cell line, positive PCR on blood, and seroconversion. This patient presented with multiorgan failure and many of the clinical manifestations of severe ehrlichial infection previously reported..$^{14-17}$ Because of the underlying CML, the patient did not present with the thrombocytopenia and leucopenia characteristic of HGE. This patient shows that given the proper epidemiological setting, the presence of leucocytosis should not exclude 
Table 3 Expansion of Anaplasma phagocytophilum in patient cells and $\mathrm{HL}-60$ cells during the first four days of culture*

\begin{tabular}{lllll}
\hline Cell type & Day 1 & Day 2 & Day 3 & Day 4 \\
\hline Total WBC count & $8.6 \times 10^{6}$ & $1.4 \times 10^{7}$ & $1.2 \times 10^{7}$ & $9.8 \times 10^{6}$ \\
Total infected WBC & $3.4 \times 10^{5}$ & $6.8 \times 10^{5}$ & $1.4 \times 10^{6}$ & $2.2 \times 10^{6}$ \\
Total HL-60 cell count & $1.4 \times 10^{6}$ & $4.4 \times 10^{6}$ & $1.8 \times 10^{7}$ & $2.5 \times 10^{7}$ \\
Total infected HL-60 cells & 0 & 0 & 0 (rare) & $2.3 \times 10^{6}$ \\
\hline
\end{tabular}

*The patient's blood was obtained during the acute phase of infection before doxycycline treatment. Total cell numbers represent the absolute number of viable cells in each flask at the different time points indicated. Numbers of infected patient's WBCs were significantly different from infected HL-60 cells at each of the first three days of incubation $\left(\mathrm{p}<0.001\right.$; Pearson $\left.\chi^{2}\right)$.

WBC, white blood cells.

HGE infection from the differential diagnosis of an acute febrile illness. ${ }^{18}$

HL-60 is the cell line most frequently used for the cultivation of A phagocytophilum. ${ }^{4}{ }^{19}$ The observation that A phagocytophilum could be propagated in vitro in the patient's own leukaemic cells was unanticipated. Under normal conditions of A phagocytophilum culture, patients' leucocytes do not survive for more than a few days, and become overgrown by the HL-60 cells (unpublished observations, 1998). This patient's cells survived until day 10 of culture, and probably beyond, in culture; furthermore, his cells supported infection earlier than did the HL-60 cells, both in the initial diagnostic culture and later in the in vitro experimental cultures. It is likely that the prolonged survival of this patient's cells was a result of their malignant nature. The higher rate of infection in the patient's leukaemic cells than in HL-60 cells in the original coculture might have been the result of the development of visible inclusions in cells originally infected in vivo, but this explanation could not account for the same observations made in the in vitro experiments. Our findings support the notion of the preferential infection of mature granulocytes by A phagocytophilum.

In agreement with previous reports,,$^{20}$ control cells from a healthy donor did not survive in culture, whereas our patient's cells were still viable at day 10. Although Yoshiie et al were able to infect normal donor granulocytes in vitro, they used cell free organisms and they examined the cells every few hours for up to 96 hours. ${ }^{21}$ Our experiment, using infected HL-60 cells that contained mostly intracellular organisms, might have required a longer incubation period to initiate (or transmit) infection, and our healthy donor cells did not survive long enough.

Analogous to our findings, Klein et al have shown that bone marrow progenitor cells (CD34+, HLA-DR+) were more susceptible in vitro to $A$ phagocytophilum infection after they were allowed to differentiate to the myelomonocytic pathway

Table 4 Comparison of the experimental infection of the patient's cells and HL-60 cells with two A phagocytophilum isolates*

\begin{tabular}{|c|c|c|c|c|c|c|}
\hline & \multicolumn{6}{|c|}{ \% Infected cells } \\
\hline & \multicolumn{2}{|l|}{ Day 4} & \multicolumn{2}{|l|}{ Day 5} & \multicolumn{2}{|l|}{ Day 6} \\
\hline & NY-33 & NY-37 & $\overline{\text { NY-33 }}$ & NY-37 & NY-33 & NY-37 \\
\hline $\begin{array}{l}\text { Patient's cells } \\
\text { HL- } 60 \text { cells }\end{array}$ & $\begin{array}{l}16 \\
0\end{array}$ & $\begin{array}{l}31 \\
0\end{array}$ & $\begin{array}{l}14 \\
1\end{array}$ & $\begin{array}{l}25 \\
1\end{array}$ & $\begin{array}{l}2 \\
0\end{array}$ & $\begin{array}{l}16 \\
0\end{array}$ \\
\hline
\end{tabular}

*Anaplasma phagocytophilum isolates are NY-33 and NY-37. The percentage of infected patient's cells was significantly different from that of infected $\mathrm{HL}-60$ cells at each of the times indicated $(p<0.001$;

Fisher's exact test). Healthy donor cells are not shown because they did not survive past day 4 of incubation. for four to five days in culture. ${ }^{22}$ Cells with increased granularity were more susceptible to infection, whereas undifferentiated cells were less susceptible. Whether A phagocytophilum infected cells in peripheral blood are derived from the infection of progenitor cells in the bone marrow or from the infection of granulocytes in peripheral locations is currently unknown. Information regarding infection of bone marrow cells in vivo is scanty, because bone marrow is not normally sampled in patients with HGE. Our patient's bone marrow was minimally infected, if at all, based on the negative PCR result and the delayed detection of culture positivity. The infected cells seen in the bone marrow smear could have been the result of contamination with peripheral blood. It could also be speculated that the apparent low infection rate of bone marrow results from the presence of only a small fraction of cells susceptible to infection out of the much larger heterogeneous cell population in bone marrow.

"The promyelocytic HL-60 cell line might not be the ideal cell line for the culture of Anaplasma phagocytophilum, but currently a more mature granulocytic cell line is not available"

Several factors could contribute to successful infection and propagation of $A$ phagocytophilum within the short lived peripheral blood granulocyte pool. In vitro and in vivo studies have shown that there is a reduction in apoptosis of infected neutrophils. ${ }^{21} 23$ It has also been reported that infected granulocytes lose PSGL-1 and L selectin, thus decreasing their binding to endothelial cells, ${ }^{24}$ and this may prolong the time that the granulocytes are present in blood. In addition, preliminary studies in our laboratory indicate that the replication time of A phagocytophilum in vitro may be as short as three hours (unpublished data, 2003).

The reason for preferential infection of later stages of the myeloid series is unclear. It might be speculated that different myeloid stages differentially express ligands necessary for the binding or internalisation of the organism. Cells from a bone marrow sample showed a slower rate of expansion of $A$ phagocytophilum infection than did the peripheral blood, suggesting that peripheral blood may be the principal site of infection and/or that the bone marrow milieu is less conducive for propagation of infection. Thus, the promyelocytic HL-60 cell line might not be the ideal cell line for the culture of A phagocytophilum, but currently a more mature granulocytic cell line is not available. Leukaemic cells induced to differentiate may be more suitable for culturing A phagocytophilum in vitro.

\section{ACKNOWLEDGEMENTS}

We thank L Zentmaier for excellent technical assistance, D Byrne for statistical analysis, and the medical and nursing staff who cared for this patient. 


\section{Take home messages}

- The occurrence of human granulocytic ehrlichiosis (HGE) in a patient with chronic myelogenous leukaemia (CML) enabled us to study whether Anaplasma phagocytophilum infects mature or immature cells

- Anaplasma phagocytophilum seems to infect mature granulocytes preferentially: the organism grew better in $\mathrm{CML}$ cells than in $\mathrm{HL}-60$ cells, there was a higher rate of infection in the patient's mature cells than in immature granulocytes before treatment, and there was a minimal level of infection of the patient's bone marrow

- The primary site of infection in HGE may be the peripheral mature granulocytic population

\section{Authors' affiliations}

M Bayard-Mc Neeley, I Chowdhury, M E Aguero-Rosenfeld, Department of Pathology, New York Medical College, Westchester Medical Center, Valhalla, New York 10595, USA

A Bansal, G Girao, C B Small, K Seiter, J Nelson, G P Wormser, Department of Medicine, New York Medical College

G Girao, C B Small, G P Wormser, Division of Infectious Diseases, New York Medical College

D Liveris, I Schwartz, Division of Biochemistry and Molecular Biology, New York Medical College

D F Mc Neeley, Department of Pediatrics, Cornell Medical Center, 525E 68th Street, New York, NY 10021, USA

\section{REFERENCES}

1 Bakken JS, Dumler JS, Chen SM, et al. Human granulocytic ehrlichiosis in the upper midwest United States: a new species emerging? JAMA 1994;272:212-18.

2 Dumler JS, Barbet AF, Bekker CPJ, et al. Reorganization of genera in the families Rickettsiaceae, and Anaplasmataceae in the order Rickettsiales: unification of some species of Ehrlichia, and Ehrlichia with Neorickettsia, designation of six new species combinations and designation of Ehrlichia equi and "HGE agent" as subjective synonyms of Ehrlichia phagocytophila. Int J Syst Evol Microbiol 2001;51:2145-65.

3 Anonymous. Notification that new names and new combinations have appeared in volume 51, part 6, of the IJSEM. Int J Syst Evol Microbiol 2002:52:5-6.

4 Goodman JL, Nelson C, Vitale B, et al. Direct cultivation of the causative agent of human granulocytic ehrlichiosis. N Engl J Med 1996;334:209-15.
5 Goodman JL, Curtis MN, Klein MB, et al. Leukocyte infection by the granulocytic ehrlichiosis agent is linked to expression of a selectin ligand. J Clin Invest 1999;103:407-12.

6 Herron MJ, Nelson CM, Larson J, et al. Intracellular parasitism by the human granulocytic ehrlichiosis bacterium through the P-selectin ligand, PSGL-1. Science 2000;288:1653-6.

7 Yago T, Leppanen A, Carlyon JA, et al. Structurally distinct requirements for binding of P-selectin glycoproteins ligand- 1 and sialyl Lewis $x$ to Anaplasma phagocytophilum and P-selectin. J Biol Chem 2003;278:37987-97.

8 Bakken JS, Krueth J, Wilson-Nordskog C, et al. Clinical and laboratory

characteristics of human granulocytic ehrlichiosis. JAMA 1996;275:199-205.

9 Aguero-Rosenfeld ME, Horowitz HW, Wormser GP, et al. Human granulocytic ehrlichiosis: a case series from a medical center in New York state. Ann Intern Med 1996; 125:904-8.

10 Lepidi $\mathrm{H}$, Bunnell JE, Martin ME, et al. Comparative pathology and immunohistology associated with clinical illness after Ehrlichia phagocytophila-group infections. Am J Trop Med Hyg 2002;62:29-37.

11 Centers for Disease Control and Prevention. Recommendations for test performance and interpretation from the second national conference on serologic diagnosis of lyme disease. MMWR Morb Mortal Wkly Rep 1995;44:590-1.

12 Sumner JW, Nicholson WL, Massung RF. PCR amplification and comparison of nucleotide sequences from the groESL heat shock operon of Ehrlichia species. J Clin Microbiol 1997;35:2087-92.

13 Aguero-Rosenfeld ME, Kalantarpour F, Baluch M, et al. Serology of cultureconfirmed cases of human granulocytic ehrlichiosis. J Clin Microbiol 2000;38:635-8.

14 Modi KS, Dahl DC, Berkseth RO, et al. Human granulocytic ehrlichiosis presenting with acute renal failure and mimicking thrombotic thrombocytopenic purpura. Am J Nephrol 1999;19:677-81.

15 Dumler JS, Bakken JS. Human ehrlichiosis: newly recognized infections transmitted by ticks. Annu Rev Med 1998:49:201-13.

16 Hardalo CJ, Quagliarello V, Dumler JS. Human granulocytic ehrlichiosis in Connecticut: report of a fatal case. Clin Infect Dis 1995;21:910-14.

17 Hossain D, Aguero-Rosenfeld ME, Horowitz HW, et al. Clinical and laboratory evolution of a culture-confirmed case of human granulocytic ehrlichiosis. Conn Med 1999:63:265-70.

18 Bakken JS, Aguero-Rosenfeld ME, Tilden RL, et al. Serial measurements of hematologic counts during the active phase of human granulocytic ehrlichiosis. Clin Infect Dis 2000;32:862-70.

19 Heimer R, Tisdale D, Dawson JE. A single tissue culture system for the propagation of the agents of human ehrlichiosis. Am J Trop Med Hyg 1998;58:812-15.

20 Colotta F, Re F, Polentarutti N, et al. A modulation of granulocyte survival and programmed cell death by cytokines and bacterial products. Blood 1992:8:2012-20.

21 Yoshiie K, Kim H-Y, Mott J, et al. Intracellular infection by the human granulocytic ehrlichiosis agent inhibits human neutrophil apoptosis. Infect Immun 2000;68:1125-33.

22 Klein MB, Miller JS, Nelson CM, et al. Primary bone marrow progenitors of both granulocytic and monocytic lineages are susceptible to infection with the agent of human granulocytic ehrlichiosis. J Infect Dis 1997; 176:1405-9.

23 Scaife H, Woldehiwet Z, Hart CA, et al. Anaplasma phagocytophilum reduces apoptosis in vivo. Infect Immun 2003;71:1995-2001.

24 Choi KS, Garyu J, Park J, et al. Diminished adhesion of Anaplasma phagocytophilum-infected neutrophils to endothelial cells is associated with reduced expression of leukocyte surface selectin. Infect Immun 2003;71:4586-94. 